\title{
An Approach to Integrating Environmental Considerations Within Managerial Decision-Making
}

Ravi Subramanian, Brian Talbot, and Sudheer Gupta

\section{Keywords:}

environmental legislation

industrial ecology

integrated product policy

nonlinear programming

operations planning

remanufacturing

:II Supplementary material is available on the JIE Web site
Address correspondence to:

Ravi Subramanian

College of Management

Georgia Institute of Technology

Atlanta, GA 30308

Ravi.Subramanian@mgt.gatech.edu

http://mgt.gatech.edu/directory/faculty/

subramanian/index.html

(C) 2010 by Yale University

DOI: $10.1111 / \mathrm{j} .1530-9290.2010 .00243 . \mathrm{x}$

Volume 14, Number 3
I

\section{Summary}

Recent environmental trends, including (I) an expansion of existing command and control directives, (2) the introduction of market-based policy instruments, and (3) the adoption of extended producer responsibility, have created a need for new tools to help managerial decision-making. To address this need, we develop a nonlinear mathematical programming model from a profit-maximizing firm's perspective, which can be tailored as a decision-support tool for firms facing environmental goals and constraints. We typify our approach using the specific context of diesel engine manufacturing and remanufacturing. Our model constructs are based on detailed interviews with top managers from two leading competitors in the medium and heavy-duty diesel engine industry. The approach allows the incorporation of traditional operationsplanning considerations - in particular, capacity, production, and inventory-together with environmental considerations that range from product design through production to product end of life. A current hurdle to implementing such a model is the availability of input data. We therefore highlight the need not only to involve all departments within businesses but also for industrial ecologists and business managers to work together to implement meaningful decision models that are based on accurate and timely data and can have positive economic and environmental impact. 


\section{Introduction}

In their quest to tackle environmental impacts at various stages in the production and distribution of manufactured goods, regulators continue to implement a spectrum of environmental policies. As a result, companies face complex tradeoffs in dealing with policy and competitive mosaics. For example, manufacturers of electrical and electronic equipment in Europe now have to comply with waste electrical and electronic equipment (WEEE; Directive 2003/108/EC) and restriction of hazardous substances (RoHS; Directive 2002/95/EC) directives, in addition to the myriad stipulations on the release of waste into discharge streams during production (EC 2008). The WEEE directive aims to encourage reuse, recycling, and recovery and to improve the environmental performance of all actors involved in the life cycles of electrical and electronic equipment. The RoHS directive restricts the use of lead, mercury, cadmium, hexavalent chromium, and polybrominated biphenyls or diphenyl ethers in electrical and electronic equipment.

Regulators have also implemented industryspecific legislation, such as the European Commission's (EC's) End-of-Life Vehicle (ELV) Directive (Directive 2000/53/EC), which requires automobile manufacturers to take back vehicles at the end of their useful life. The primary rationale for such legislation is to provide incentives to manufacturers to design environmentally more benign products. In the United States, several states, including California, Maine, Maryland, and Washington, have implemented various environmental laws that provide similar incentives to manufacturers. The EC legislation with potentially the widest impact is Registration, Evaluation, Authorization and Restriction of Chemicals (REACH; Directive 2006/121/EC), which went into effect on June 1, 2007. This directive requires the registration and testing of more than 30,000 chemicals and the reduction or replacement of those found to be particularly harmful to human health. These examples are only a few of the numerous regulations that manufacturers around the world have to comply with today.

Within the past few years, there has been a trend to supplement existing and planned command-and-control rules with market-based programs, which further complicates but also expands the array of choices that managers have in responding to environmental pressures. The first major market-based program was the cap-andtrade system for sulfur dioxide and nitrogen oxides under the U.S. Clean Air Act Amendments of 1990 (EPA 2005). Although this legislation affects only the U.S. electric-power-generating industry, its success has motivated the adoption of cap-and-trade programs for a number of other pollutants around the world. The most notable example to date is the greenhouse gas Emissions Trading Scheme (ETS; Directive 2003/87/EC), which affects more than 12,000 manufacturers and power generators in the European Union (EU), as an important step toward meeting the requirements set forth by the Kyoto Protocol. In the United States, several regional initiatives that rely on cap-and-trade programs have been proposed to curb greenhouse gas emissions. Examples include the Regional Greenhouse Gas Initiative (RGGI) in the Northeast; California's Global Warming Solutions Act (AB 32, 2006); the Western Climate Initiative (WCI) among states in the western United States and several provinces in Canada, including British Columbia, Ontario, Quebec, and Manitoba; and the recently announced Midwestern Climate Accord among several states in the Midwest, including Michigan, Illinois, Iowa, and Minnesota.

Analogous to the manner in which industrial ecologists comprehensively assess life cycle impacts of product systems, firms as well as policy makers are now recognizing the need to holistically address environmental decisions and targets across various product life cycle stages. Life cycle assessment (LCA) methods provide a systematic accounting of environmental burdens and impacts for a defined product system (Smith and Keoleian 2004). More often than not, the industrial ecologist's view of the product life cycle is more extensive than that of an individual firm, which might be just one of the many links in the value-adding chain from virgin material extraction to final product disposal or recovery.

Recent environmental regulations in the EU, the United States, Canada, Japan, Korea, and elsewhere force individual companies to expand their view of the product life cycle by making them responsible for environmental impacts 
beyond factory gates (e.g., see Scheer and Rubik 2005). Indeed, extended producer responsibility (EPR) programs, such as the ELV directive, seek to give producers appropriate incentives and signals concerning the life cycle environmental impacts of their products. Moreover, the EC is actively pursuing the broader concept of integrated product policy (IPP). IPP seeks to minimize products' life cycle environmental impacts by combining instruments such as economic incentives, substance bans, voluntary agreements, environmental labeling, and product design guidelines, while also emphasizing competitiveness concerns. IPP pilot projects involving various stakeholders, including manufacturers, suppliers, governmental agencies, customers, and nongovernmental organizations (NGOs), are currently underway (Environmental Resources Management 2005; Nokia Corporation 2005). Product-oriented policies, such as IPP, impact the value proposition of businesses and necessitate the incorporation of environmental aspects into strategic thinking. In its green paper on IPP, the EC recognizes the need to develop methodologies that enable a better understanding of the various drivers of environmental decisions by businesses (Tukker 2006; EC 2001).

Today, it is clear that the connection between a firm's operational decisions and its environmental performance is immediate (Tukker and Jansen 2006). Although environmental considerations often impose additional costs and constraints on production systems, they also open up new opportunities that, if properly exploited, can lead to better financial performance while also improving the firm's environmental impact. Joint operational and environmental decision-making requires the understanding and modeling of complex trade-offs, which, in turn, requires a rich and pliable framework capable of treating nonlinear interactions (Bloemhof-Ruwaard et al. 1995). Senior managers in many industries lack such a framework and practical tools that can help them set priorities and make decisions that are both financially and environmentally sound. To address this need, we develop a nonlinear mathematical programming model from a profit-maximizing firm's perspective, which can be tailored as a decision-support tool for firms facing environmental goals and constraints. Figure 1 outlines the scope of our model, including the specific product life cycle stages that are captured.

Although we present a characteristic model for a specific industry context, the approach in itself is sufficiently flexible to accommodate a range of applications. It allows for the treatment of a spectrum of regulatory instruments, such as design standards, product take-back, disposal costs, emissions limits and charges, and environmental end-user fees, together with compliance options, such as product design, investment in abatement technologies, procurement of emissions allowances, and adjustment of the product mix (including the mix of new and

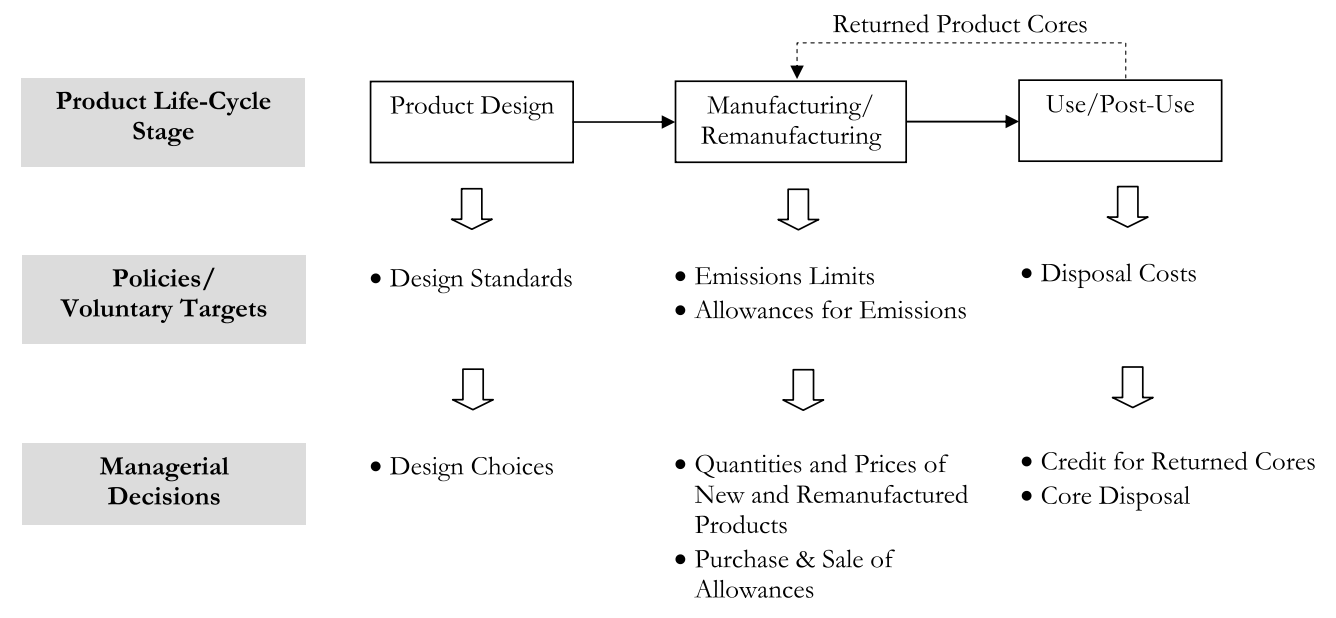

Figure I Scope of the model. 
remanufactured products) or raw material inputs. It also facilitates consideration of key strategic aspects, such as product pricing, consumer demand, competition, and the cannibalization of new products by remanufactured products. From a methodological perspective, our work demonstrates how environmental targets and firms' compliance strategies can be modeled effectively with the classical operations research tool of mathematical programming. The model's ability to treat nonlinear relationships makes it amenable to refinement and managerial application. The work is timely and pertinent to practitioners, many of whom are beginning to deal with complex tradeoffs in complying with environmental regulations at various stages in the production and consumption of their products.

The article is organized as follows. We first provide a review of the relevant literature on environmental decision-making and operations planning. Next, we discuss the need for the modeling approach presented in the article and develop the representative model, including its decision variables, parameters, relationships, constraints, and objective function, on the basis of information gathered from interviews. Furthermore, we discuss the current hurdles in implementing such a model. We then solve the model using illustrative data to highlight the importance of holistically treating environmental factors and operational decisions. Of the appendices referenced in the article, Appendices A, B, and C are included at the end of the article, whereas Appendices D, E, F, and G are included in the Supplementary Material on the Web.

\section{Literature Review}

This article builds on three primary streams of literature: (1) the use of mathematical programming to model environmental decision-making, (2) environmentally conscious manufacturing and reverse supply chains, and (3) aggregate production planning (APP). Mathematical programming has been used extensively to model environmental decision-making since the first papers appeared on water, air, and land pollution in the early 1960s. Greenberg (1995) provides an excellent survey of the related literature, with an annotated bibliography of more than 335 articles, books, and manuscripts that fall into two major categories-those that focus on the effective management of local area resources, and those that address aggregate, typically country-level economic and environmental policies. The common theme of this research is achieving certain environmental qualities at minimum economic cost. Applications range from the highly specific, such as designing a water treatment plant, to general equilibrium models that examine taxation, pollution credits, and other policy instruments for an entire economy. In virtually every instance, this research takes a public policy perspective, not the perspective of a profit-making firm. Research that could be of use to both public agencies and firms typically deals with the management of specific natural resources, such as forests or agricultural products. Since Greenberg's review, this stream of research has expanded substantially, with the development of increasingly sophisticated modeling tools and solution techniques that take into account multiple goals, multiple stakeholders, and lack of information but maintain a continued focus on policy-making. Mendoza and Martins (2006) present a review of more than 100 papers of this genre.

The literature on environmentally conscious production and product recovery that focuses on recycling and remanufacturing, can be traced back to the 1970s and early 1980s (e.g. Ginter and Starling 1978; Lund 1984). Subsequently, there has been an explosion of interest, and substreams of literature now focus on particular aspects, such as product design, process design, capacity and production planning, and reverse logistics. Within these topical areas, the articles range from policy oriented to very detailed and product or industry specific and from highly abstract to very practical. From a methodological perspective, two articles are relevant. Spengler and colleagues (1997) develop mixed-integer linear programs to analyze two industrial-planning problems: the recycling of industrial by-products, and the dismantling and recycling of building demolition products. They successfully apply their models to determine the location and capacity allocations of recycling installations for the steel industry in Germany and to the demolition and recycling of buildings in the Upper Rhine Valley in France and Germany. Rajaram and 
Corbett (2002) develop a nonlinear integer program that they updated and used repeatedly over a 5 -year period to successfully guide the redesign of a complex wheat starch processing facility in the Netherlands. Their efforts led to significant reductions in water and energy consumption at the facility. It should be noted that although Spengler and colleagues (1997) and Rajaram and Corbett (2002) use mathematical programming, both sets of authors focus on manufacturing process design, the former from a regional industrial policy perspective, and the latter from an individual firm perspective.

A comprehensive survey of the literature on environmentally conscious production and product recovery is provided by Gungor and Gupta (1999), who review and categorize more than 300 papers. More recently, informative overviews of the managerially focused product recovery literature have been presented by Atasu and colleagues (2008), Guide and Wassenhove (2006a, b), Kleindorfer and colleagues 2005, and Corbett and Kleindorfer (2001a, b). This literature addresses a range of important strategic and tactical issues, such as product and process design, supply chain contracting, production planning, and inventory management, with an emphasis on the design and management of reverse supply chains.

The oldest relevant literature stream deals with APP. APP is an important and difficult operations-planning activity that involves determining a company's optimal production, work force, inventory, and capacity levels over a medium-term planning horizon to meet strategic goals (Heizer and Render 2005; Wang and Liang 2005). Typical planning horizons for APP are 612 months into the future, with rolling updates of the plan. In hierarchical operations-planning schemes, aggregate production plans provide a framework and guidance for more detailed production planning and scheduling. The APP literature has evolved significantly since the pioneering work of Holt and colleagues $(1955,1956)$, and a number of graphical, mathematical, and heuristic techniques have been developed and implemented to solve APP problems, reviews of which can be found in articles by Nam and Logendran (1992) and Mula and colleagues (2006). Recent advances in this field mirror the changes in the first literature stream discussed in this section; researchers are developing more sophisticated models to incorporate real-world complexities and to take advantage of dramatic improvements in solution algorithms and computing power. An example of this trend is work by Wang and Liang (2005), who develop a fuzzy multiobjective linear programming model for solving the multiproduct APP problem that takes into account all the traditional considerations, such as inventory levels, back-ordering, and labor levels, but adds multiple fuzzy goals. Another illustration of this trend is work by Fahimnia and colleagues (2007), who propose a genetic algorithm for solving the traditional APP problem.

To the best of our knowledge, none of the articles in the traditional APP literature deals specifically with environmental considerations, with fairly recent exceptions. Wu and Chang (2004) use the gray compromise programming approach to model production planning for a textile dying firm in Taiwan over a 1-year horizon in monthly time buckets, with three objective functions: (1) minimize total variable production cost, (2) maximize utilization efficiency of production equipment, and (3) minimize inventory cost. Three traditional classes of APP constraints are included: availability of labor, production capacity, and inventory space. Two categories of environmental considerations are modeled: water usage, which varies by product type, season, and geographic location of the facility, and emissions and effluents in air and waste water streams, which vary by type of product (e.g., $100 \%$ cotton versus synthetic) and production process used. The authors argue that given the uncertainties in specifying some of the model parameters, the gray programming approach is a superior alternative to goal programming. The article develops production plans that allow managers to make informed decisions given all the trade-offs.

Another exception is the article by Stuart and colleagues (1999). Although the authors focus on longer time horizons than is typical of APP, the underlying approach and research questions are very much in the spirit of APP. Stuart and colleagues propose a mixed-integer programming model that is designed to select products and processes from sets of alternatives as well as 
determine production quantities over a multiyear product life cycle time horizon subject to various strategic and operational constraints. They take into account environmental considerations, such as material and energy consumption, process waste generation, and packaging, and explicitly link assembly and take-back activities. We believe this is by far the most comprehensive APP. like decision support model in the literature that includes environmental considerations.

Our article adds to the above literature streams in different ways. It adds to the first literature stream of environmental decision-making in that it takes the perspective of a for-profit manufacturing firm that has to develop detailed production plans on an ongoing basis in light of many complex trade-offs (identified in our article through detailed interviews with managers in a specific industry), including important environmental considerations, rather than the perspective of a public agency facing a long-term policy design and implementation problem. Our work, however, takes a similar underlying mathematical programming approach. Our work is distinct from the bulk of the current environmentally conscious manufacturing and reverse supply chain literature in that it is designed to provide the framework for an active decision support system for ongoing production planning rather than an abstract mathematical or conceptual model for developing structural insights. Our research most closely extends the APP literature, which, with the appearance of the works by Wu and Chang (2004) and Stuart and colleagues (1999), is now becoming intimately linked to the environmentally conscious manufacturing literature. Our work extends the APP literature by explicitly linking production decisions and product market dynamics for the first time and by explicitly incorporating into production planning the costs, constraints, and decision variables imposed by an emissions-permit-based program. Unlike previous APP research, which assumes product demands and prices to be exogenous, we model demand functions for new and remanufactured products, with prices for both as decision variables. Finally, in addition to the normal APP decision variables that influence production quantities per period, we include decision variables for the initial design choices of product performance and remanufacturability and the in- centive to be offered for cores to be returned for remanufacturing.

In concluding our review of the relevant literature, we note that our work is also an attempt at bridging the relevant literature discussed above, with the industrial ecology literature-in particular, LCA-related research. LCAs have great potential to facilitate managerial decision-making through the detailed information they provide in relation to environmental outcomes along multiple dimensions, such as carbon impact by life cycle stage (Matthews and Lifset 2007).

\section{The Need for a Holistic Model}

Although managerial decision-making is challenging in its own right, present-day environmental policies force firms to address numerous additional trade-offs. The subset of the product life cycle relevant to managerial decision-making continues to expand as environmental policymaking increasingly attributes to manufacturers responsibilities for the life cycle environmental impacts of products. We typify our approach using the specific context of diesel engine manufacturing and remanufacturing. Our model constructs are based on detailed interviews with top managers from two leading competitors (labeled as Companies $\mathrm{A}$ and $\mathrm{B}$ in our discussions and model development) in the medium and heavyduty diesel engine industry.

Our interviews followed a semistructured format. We sent a set of questions to each interviewee in advance and followed it up with a series of phone interviews, during which we let the interviewees talk about our specific questions as well as any other related issues. Thereafter, we sent follow-up questions by e-mail so respondents could clarify or expand on certain specifics. Appendix $\mathrm{A}$ includes the questions that we asked in advance of our phone interviews as well as the follow-up questions that we asked by e-mail. ${ }^{1}$

Although the companies interviewed had a sense of the various types of interactions between operations-planning and environmental factors, no holistic effort was currently in place to characterize the interactions and tie the factors together. Company A, for example, has a department devoted to assessing the environmental impacts of its products. There is limited meshing of the 
department's actions and operations-planning decisions, however. As a result, the feeling is that monetary as well as environmental benefits are not fully realized. Environmental considerations are primarily tied into the design phase to ensure that legislated standards are met but are not actively treated in operational-planning decisions, such as the product mix. For example, both companies have put voluntary corporate programs in place to reduce their carbon impact. Because remanufacturing requires significantly less energy than manufacturing new, it would make sense to tie remanufacturing decisions with voluntary commitments. It is worth noting that Company B owns foundries in Europe that are affected by the ETS, which is aimed at limiting carbon dioxide $\left(\mathrm{CO}_{2}\right)$ emissions. Environmental considerations do not currently drive remanufacturing decisions at Company B, however; remanufacturing is not pursued if the associated cost is expected to be more than a specified percentage of the cost of producing new.

With respect to the coordination of manufacturing and remanufacturing decisions, remanufacturing operations did not historically affect decisions related to new products at the companies interviewed. Although there is currently some level of coordination, the sense is that manufacturing and remanufacturing executives are heavily focused on their respective operations. For example, Company A recognizes the issue of new and remanufactured products competing for capacity, but it lacks a practical tool to intelligently decide how scarce capacity should be allocated. With respect to product pricing, the companies use price targets for remanufactured products (i.e., the price of a remanufactured product is a specified percentage of the price of its new counterpart-currently in the range of $60 \%$ to $85 \%$ ). The companies believe that pricing decisions should be made more rigorously, however. Additionally, both companies offer monetary incentives to drive return flows of used product cores. Company A, for example, believes that the current method of offering core credit is much less scientific than it needs to be. The sense is that the credit offered for cores should relate to inventory and planned production levels, but related decision-making tools are lacking.

\section{Model Development}

In this section, rather than just presenting the final normative form of our proposed model, we progressively build the model by motivating and characterizing the various decisions, constraints, and interrelationships involved in decision-making at the two companies interviewed. In developing our multiproduct, multiperiod manufacturing-remanufacturing model from a company's perspective, we use the subscript $i \in\{1 \ldots M\}$ to denote the index of the product and $t \in\{1 \ldots T\}$ to denote the time period (e.g., months or years). $M$ indicates the number of products (e.g., within a product family), and $T$ indicates the time horizon over which decisions are to be optimized. We use the subscripts $n$ and $r$ to refer to new and remanufactured products, respectively. The model development reflects numerous trade-offs across product life cycle stages - starting with product design, through production, to the end of the product's economic life. The functional forms used to model various relationships are structurally ${ }^{2}$ consistent with the interviewed managers' experience. Specific values of the parameters of the functional specifications are currently unknown but can be estimated with varying levels of effort (discussed later in the Implementation section). The notation used in this section is summarized in Appendix B.

\section{Product Design}

\section{Product Performance}

Diesel engine emissions and fuel economy standards are specified by legislation. The fuel mileage of the engine is a primary design attribute that directly affects engine emissions. For exposition, we label this design attribute as performance. Let $Q_{i, \text { std }}$ denote the standard (or lower bound) of performance for product $i$ prescribed by regulation, and let $Q_{i 0}$ denote the manufacturer's choice of performance of product $i$. The subscript 0 in $Q_{i 0}$ denotes that the design decision is made at the beginning of the planning horizon. Let $Q_{i 0}^{C}$ denote the performance of the competitor's corresponding product $i$. Consistent with the diminishing returns to design investments, we model the design cost of performance for product $i$ as $\left[\xi_{1 i} Q_{i 0}\right]^{2}$, where $\xi_{1 i}>0$. 
Decision 1: Determine the performance of product $i: Q_{i 0} \geq 0$.

Constraint 1: Performance standard for product $i: Q_{i 0} \geq Q_{i, \text { std }}$.

Cost 1: Design cost of performance for product $i:\left[\xi_{1 i} Q_{i 0}\right]^{2}$.

\section{Product Remanufacturability}

Although existing product take-back laws do not currently affect either company's products, there are concerns that, sooner or later, entire product families will be subject to take-back laws. Despite the absence of take-back requirements, both companies have been collecting engines from the marketplace and remanufacturing them, due to the associated value in doing so. Engine remanufacturing requires between $80 \%$ and $90 \%$ less energy than manufacturing new, and the revenue generated in the after-market by remanufacturing is attractive. Remanufacturing also costs less, due to the reuse of materials and the relatively lower processing costs. Both Company $\mathrm{A}$ and Company $\mathrm{B}$ have explicit designfor-remanufacturability (DfR) criteria, including designing wall thicknesses so that the engine block can be milled or bored down during the remanufacturing process, allowing for the building up of material when necessary, and, in general, designing products that are easy to clean and machine during remanufacturing. Other DfR efforts include informational tools, such as engine control units (ECUs) and fatigue clocks built into the engine, which record duty cycles and other pertinent information to facilitate remanufacturing.

Therefore, in addition to the design choice of performance described earlier, we also explicitly model the choice of remanufacturability. Let $\Theta_{i 0} \in\left[0,1-\Theta_{i B}\right]$ denote the manufacturer's choice of remanufacturability of product $i$, representing the fraction (e.g., by weight) of a core of product $i$ that can be effectively remanufactured beyond the inherent level (i.e., absent any investment in remanufacturability) $\Theta_{i B}$. For example, when greater remanufacturability is built into the design of the engine, major castings or forgings, such as blocks, cylinder heads, crankshafts, and connecting rods, can be more effectively remanufactured. We model the design cost of remanu- facturability for product $i$ as $\left[\xi_{2 i} \Theta_{i 0}\right]^{2}$, where $\xi_{2 i}$ $>0$.

Decision 2: Determine the remanufacturability of product $i: 0 \leq \Theta_{i 0} \leq 1$.

Cost 2: Design cost of remanufacturability for product $i:\left[\xi_{2 i} \Theta_{i 0}\right]^{2}$.

\section{Manufacturing and Remanufacturing Costs}

Remanufacturability often adversely affects unit production costs for new engines. For example, with the use of metal removal technologies to remanufacture engine components, the extra casting or forging thicknesses result in increased material content and, hence, increased costs. Additionally, to capture the increasing costs in relation to performance, we model the unit cost of manufacturing a new product $i$ in period $t$ as $c_{i t n}=\tilde{c}_{i t n 0}+\tilde{c}_{i t n} Q_{i 0}^{2} \Theta_{i 0}$, where $\tilde{c}_{i t n o}, \tilde{c}_{i t n}>0$. We denote $f_{i t n}$ as the fixed cost of manufacturing new product $i$ in period $t$.

Conversely, for engines in the same displacement family, remanufacturing costs are not adversely affected by the engine's performance. Because the variable cost of remanufacturing decreases with remanufacturability, we model the unit cost of remanufacturing product $i$ in period $t$ as $c_{i t r}=\tilde{c}_{i t r o}+\tilde{c}_{i t r}\left[1-\left(\Theta_{i 0}+\Theta_{i B}\right)^{2}\right]$, where $\tilde{c}_{i t r o}, \tilde{c}_{i t r}>0$. We denote $f_{i t r}$ as the fixed cost of remanufacturing product $i$ in period $t$. Due to its labor intensity, remanufacturing has lower fixed costs than manufacturing new.

Relationship 1: Unit cost of manufacturing a new product $i$ in period $t: c_{i t n}=\tilde{c}_{i t n o}+\tilde{c}_{i t n} Q_{i 0}^{2} \Theta_{i 0}$.

Relationship 2: Unit cost of remanufacturing product $i$ in period $t: c_{i t r}=\tilde{c}_{i t r}+\tilde{c}_{i t r}\left[1-\left(\Theta_{i 0}+\right.\right.$ $\left.\left.\Theta_{i B}\right)^{2}\right]$.

\section{Product Mix}

The product mix decision involves determining the quantities of new and remanufactured products to produce in each period. The choice of production quantities is intricate, because products have different manufacturing and remanufacturing costs, compete for capacity, are subject to different demand parameters, are associated with different levels of emissions, face different 
core disposal costs (or salvage values), have different economic lives, and have different inventory holding and back-ordering costs. As mentioned earlier, remanufacturing is attractive due to its profit potential. It also, however, has the fundamental environmental benefit of lower energy use. About $95 \%$ of $\mathrm{CO}_{2}$ emissions during engine manufacturing can be attributed to energy consumption, and remanufacturing requires between $80 \%$ and $90 \%$ less energy than manufacturing new. Hence, remanufacturing should be favored for meeting either voluntary or mandated limits on $\mathrm{CO}_{2}$ emissions.

We denote $X_{i t}$ and $Y_{i t}$, respectively, as the number of units of product $i$ manufactured and remanufactured in period $t$. Let $h_{i t n}, h_{\text {itr }}$, and $h_{\text {itc }}$, respectively, denote the unit inventory holding costs of new product $i$, remanufactured product $i$, and cores of product $i$ in period $t$. Let $u_{i t n}$ and $u_{\text {itr }}$, respectively, denote the unit cost of backordering customer demand for new and remanufactured product $i$ in period $t$. Additionally, current engine design tools are reasonably accurate in predicting the economic life of an engine; we denote $\tau_{i}$ as the economic life of product $i$ (measured in time periods).

Nonremanufacturable components of cores, as well as entire cores that the companies decide not to remanufacture at all (perhaps due to holding costs), undergo both scrapping and disposal of certain parts. Often, the cast iron, steel, and aluminum in a core can be profitably scrapped. Disposal costs are incurred for dirt that comes off the core and for certain consumable parts, such as gaskets. Let $\rho_{i t}$ denote the net unit cost of disposing of (or, equivalently, the net salvage value per unit of) cores of product $i$ in period $t$. Let $W_{i t}$ denote the number of entire cores of product $i$ disposed of in period $t$.

Decision 3: Determine the production quantities of new and remanufactured products in period $t: X_{i t}, Y_{i t} \geq 0$.

Decision 4: Determine the number of cores to be disposed of in period $t: W_{i t} \geq 0$.

Cost 3: Total cost of manufacturing new product $\mathrm{i}$ in period $t: \delta_{i t n} f_{i t n}+c_{i t n} X_{i t}$, where $\delta_{i t n}=1$ if $X_{i t}>0 ; 0$ otherwise.

Cost 4: Total cost of remanufacturing product $i$ in period $t: \delta_{i t r} f_{i t r}+c_{i t r} Y_{i t}$, where $\delta_{i t r}=1$ if $Y_{i t}>0 ; 0$ otherwise.

\section{Manufacturing and Remanufacturing Capacity}

The two principal types of capacity in manufacturing and remanufacturing are machining and assembly. Although the assembly operation is more labor intensive in remanufacturing than in manufacturing new, some assembly capacity can be shared across remanufacturing and manufacturing. This is not typical of machining capacity, however. We denote $K_{a t}$ as the total assembly capacity available in period $t, K_{m t n}$ as the machining capacity available for manufacturing new in period $t$, and $K_{m t r}$ as the machining capacity available for remanufacturing in period $t$.

New and remanufactured versions of a product consume different amounts of capacity. For example, remanufacturing requires a smaller amount of machining capacity as compared with manufacturing new. Therefore, we denote $k_{\text {ain }}$ and $k_{\text {air }}$, respectively, as the manufacturing and remanufacturing assembly capacities consumed per unit of product $i$. Similarly, $k_{\min }$ and $k_{\text {mir }}$ denote the machining capacities consumed per unit of product $i$.

Constraint 2: Assembly capacity available in period $t: \sum_{i=1}^{\mathrm{M}}\left[k_{a i n} X_{i t}+k_{a i r} Y_{i t}\right] \leq K_{a t}$.

Constraint 3: Machining capacity available for manufacturing a new product in period $t$ : $\sum_{i=1}^{M} k_{\min } X_{i t} \leq K_{m t n}$.

Constraint 4: Machining capacity available for remanufacturing in period $t: \sum_{i=1}^{\mathrm{M}} k_{\text {mir }} Y_{i t} \leq$ $K_{m t r}$.

\section{Pricing and Demand}

Price adjustments are made on a periodic basis at the companies interviewed (annually, in the case of Company A). Exceptions to this periodicity include adjustments to compensate for extraordinary fluctuations in raw material costs. We denote $P_{i t n}$ and $P_{i t r}$, respectively, as the prices of new and remanufactured product $i$ in period $t$.

Price differentials between new and remanufactured engines are known to affect respective customer demands. Also, different markets are known to have varying levels of access to and acceptability of remanufactured engines. Performance is a major driver of demand in developed markets, as opposed to price in developing 
markets. ${ }^{3}$ Nevertheless, customers in developed countries are known to embrace remanufactured engines more than customers in developing countries. ${ }^{4}$ We model the demands for new and remanufactured versions of a product in each period as functions of prices of the versions, product performance, and the price $\left(P_{i t}^{C}\right)$ and performance $\left(Q_{i 0}^{C}\right)$ of the competing product offered by the other company.

Decision 5: Determine the prices of new and remanufactured product $i$ in period $t: P_{i t n}, P_{i t r} \geq$ 0 .

Relationship 3: Demand for new product $i$ in period $t: d_{i t n}=a_{i t n}-b_{i t n} P_{i t n}+b_{i t n r} P_{i t r}+b_{i t n}^{\mathrm{C}} P_{i t}^{\mathrm{C}}$ $+b_{i t n q} Q_{i 0}-b_{i t n q}^{C} Q^{C}{ }_{i 0} \geq 0$; demand for remanufactured product $i$ in period $t: d_{i t r}=a_{i t r}-b_{i t r} P_{i t r}+$ $b_{i t r n} P_{i t n}+b_{i t r}^{\mathrm{C}} P_{i t}^{\mathrm{C}}+b_{i t r q} \mathrm{Q}_{i 0}-b_{i \text { trq }}^{\mathrm{C}} \mathrm{Q}_{i 0}^{\mathrm{C}} \geq 0$. All $a_{[]}$ (market potentials) and $b_{[]}$(sensitivity parameters) $\geq 0$.

Relationship 3 captures the cannibalization effect that remanufactured products may have on the demand for new products. Parameters $b_{i t n r}$ represent sensitivity of demand for new products to the prices of remanufactured products in period $t$. Similarly, parameters $b_{\text {itrn }}$ represent sensitivity of demand for remanufactured products to the prices of new products in period $t$. Thus, new and remanufactured products are partial substitutes. In general, demand for a product is more sensitive to changes in its own price than to changes in prices of substitutes (i.e., $b_{i t n}>b_{i t n r}$ and $\left.b_{i t r}>b_{i t n r}, \forall i, t\right)$. As mentioned above, markets differ in their preferences and price sensitivities for new and remanufactured products.

Revenue 1: Revenues from new and remanufactured product $i$ in period $t: P_{i t n} d_{i t n}+P_{i t r} d_{i t r}$.

Relationship 4: Inventory position ${ }^{5}$ of new product $i$ at end of period $t: I P_{i t n}=I P_{i, t-1, n}+$ $X_{i t}-d_{i t n}$; inventory of new product $i$ at end of period $t: I_{i t n}=\left[I P_{i t n}\right]^{+}$; back-ordered quantity of new product $i$ at end of period $t: \sigma_{i t n}=\left[I P_{i t n}\right]^{-}$.

Relationship 5: Inventory position of remanufactured product $i$ at end of period $t: I P_{i t r}=I P_{i, t-1, r}$ $+Y_{i t}-d_{i t r}$; Inventory of remanufactured product $i$ at end of period $t: I_{i t r}=\left[I P_{i t r}\right]^{+}$; back-ordered quantity of remanufactured product $i$ at end of period $t: \sigma_{i t r}=\left[I P_{i t r}\right]^{-}$.

Cost 5: Costs of backordering new and remanufactured product $i$ in period $t: u_{i t n} \sigma_{i t n}+u_{i t r} \sigma_{i t r}$.
Relationship 6: Sales of new product $i$ in period $t: S_{i t n}=I_{i, t-1, n}+X_{i t}-I_{i, t, n}$; sales of remanufactured product $i$ in period $t: S_{i t r}=I_{i, t-1, r}+Y_{i t}-$ $I_{i, t, r}$.

\section{Core Credit}

Return flows of end-of-life engine cores can be influenced by monetary incentives. We denote $\Psi_{i t}$ as the credit offered per returned core of product $i$ in period $t .{ }^{6}$ By offering such incentives, the companies are better able to secure control over cores, which are regarded as the "lifeblood" of remanufacturing operations and which competing third-party engine remanufacturers and rebuilders simultaneously seek out. Thus, endof-life core returns are sensitive to the core credit offered. We model core returns of product $i$ in period $t$ as an increasing function of the core credit offered.

Return flows of cores involve fixed costs related to (1) facilities for transporting, receiving, inspecting, and storing cores; (2) the materials handling infrastructure; and (3) the information systems infrastructure required for inventory management as well as for the transactional aspects of receiving, inspecting, and issuing credit for returned cores. We denote $f_{\text {itc }}$ and $c_{\text {itc }}$, respectively, as the fixed and variable costs of collecting cores of product $i$ in period $t$.

Decision 6: Determine the credit per unit of returned core of product $i$ in period $t: \Psi_{i t} \geq 0$.

Relationship 7: Returns of cores of product $i$ in period $t: R_{i t}=\lambda_{i t} \Psi_{i t}\left[S_{i, t-\tau_{i}, n}+S_{i, t-\tau_{i}, r}\right]$, where $\lambda_{i t} \in[0,1]$ reflects the sensitivity of core returns to the credit offered. ${ }^{?}$

Constraint 5: Possible returns of cores of product $i$ in period $t: R_{i t} \leq S_{i, t-\tau_{i}, n}+S_{i, t-\tau_{i}, r}$.

Cost 6: Total cost incurred for returned cores of product $i$ in period $t: \delta_{i t c} f_{i t c}+\left(\Psi_{i t}+c_{i t c}\right) R_{i t}$; $\delta_{i t c}=1$ if $R_{i t}>0 ; 0$ otherwise.

Cost 7: Total disposal cost incurred for cores of product $i$ in period $t: \rho_{i t}\left[\left\{1-\left(\Theta_{i 0}+\Theta_{i B}\right)\right\} Y_{i t}\right.$ $\left.+W_{i t}\right]$ (also see Decision 4).

Relationship 8: Inventory of cores of product $i$ at end of period $t$, after core returns, disposal, and remanufacture: $I_{i t c}=I_{i, t-1, c}+R_{i t}-W_{i t}-Y_{i t}$.

Constraint 6: Number of cores of product $i$ that can possibly be disposed of in period $t: W_{i t} \leq$ $I_{i, t-1, c}+R_{i t}$. 
Constraint 7: Number of cores of product $i$ that can possibly be remanufactured in period $t: Y_{i t} \leq$ $I_{i, t-1, c}+R_{i t}-W_{i t}$.

Cost 8: Cost of holding inventories of new product $i$, remanufactured product $i$, and cores of product $i$ in period $t: h_{i t n} I_{i t n}+h_{i t r} I_{i t r}+h_{i t c} I_{i t c}$.

\section{Limits on Emissions}

The principal pollutant attributable to engine manufacturing and remanufacturing is $\mathrm{CO}_{2}$ from the energy consumed. Both companies interviewed have set voluntary targets of reductions in carbon emissions attributable to their facilities. In particular, Company A has committed to reduce $\mathrm{CO}_{2}$ emissions due to its facilities (as of 2005) by 25\% (normalized by sales) by 2010 . Company B has recently started measuring carbon impact and has self-imposed goals on reducing this impact. Moreover, as noted earlier, Company B owns foundries in Europe that are affected by the EU-wide cap-and-trade program (ETS), in which affected companies are required to account for $\mathrm{CO}_{2}$ emissions with the requisite number of allowances. Let $e_{i n}$ and $e_{i r}$, respectively, denote the $\mathrm{CO}_{2}$ emissions attributable to the manufacture and remanufacture of a unit of product $i$. Let $l_{t}$ denote the voluntary limit on such emissions in period $t .^{8}$ Let $B_{t}$ and $V_{t}$, respectively, denote the number of allowances purchased and sold in period $t$. Let $\eta_{t}$ (assumed to be $>l_{t}$ ) denote the number of allowances available for purchase in the market and $\phi_{t}$ denote the market price of an allowance in period $t$.

Relationship 9: Total $\mathrm{CO}_{2}$ emissions attributable to manufacturing and remanufacturing in period $t, E_{t}=\sum_{i=1}^{M}\left(e_{i n} X_{i t}+e_{i r} Y_{i t}\right)$.

Constraint 8: Emissions limit: $E_{t} \leq l_{t}$.

Decision 7: Determine the number of allowances to be purchased in period $t$ $: B_{t} \geq 0$, and the number of allowances sold in period $t: V_{t} \geq 0$.

Cost 9: Cost of allowances purchased in period $t: \phi_{t} B_{t}$.

Constraint 9: Market availability of allowances in period $t: B_{t} \leq \eta_{t}$.

Relationship 10: Inventory of allowances at end of period $t: \beta_{t}=\beta_{t-1}+B_{t}-E_{t}-V_{t}$.

Constraint 10: Allowances on hand in period $t: E_{t} \leq \beta_{t-1}+B_{t}$.
Constraint 11: Number of allowances that can possibly be sold in period $t: V_{t} \leq \beta_{t-1}+B_{t}-E_{t}$.

Revenue 2: Revenue from sale of allowances in period $t: \phi_{t} V_{t}$.

\section{Initial and Terminal Conditions}

For model completeness, we specify the following null initial and terminal conditions. In operational use, the righthand sides of the initial conditions would take on the actual values at the time of model implementation, whereas the terminal conditions would reflect acceptable bounds for the end of the planning horizon.

Initial conditions (zero inventories and zero core returns, disposal, and remanufacturing):

$$
\begin{array}{cl}
I P_{i, 0, n}, I P_{i, 0, r}=0 ; & i=1,2, \ldots, M \\
I_{i k c}, R_{i k}, W_{i k}, Y_{i k}=0 ; & i=1,2, \ldots, M ; \\
& k=1,2, \ldots, \tau_{i} \\
\beta_{0}=0 &
\end{array}
$$

Terminal conditions (zero back-orders):

$$
\sigma_{i T n}, \sigma_{i T r}=0 ; \quad i=1,2, \ldots, M
$$

\section{Complete Model}

In this section, we present the complete model that assembles together the revenues, costs, relationships, constraints, and conditions identified in the preceding discussion. Subsequent to the initial design choices of performance and remanufacturability, we assume the following sequence of activities in each decision period. Collected cores become available to the manufacturer; cores from inventory may be disposed of; new and remanufactured products are produced; nonremanufacturable components are disposed of; emissions allowances are purchased, applied, and sold; prices for new and remanufactured products are offered, and demands are realized; and, finally, inventories and associated costs are assessed. The elements captured in the model are summarized in figure 2. Appendix B summarizes the notation used in the model, and Appendix C lists additional assumptions made.

Expressed in words, the manufacturer maximizes its discounted total profit - we denote the 


\begin{tabular}{|c|c|c|c|}
\hline Model Component & Operational Elements & Environmental Elements & Strategic Elements \\
\hline Decision Variables & $\begin{array}{l}\text { - Quantities of new and } \\
\text { remanufactured products }\end{array}$ & $\begin{array}{l}\text { - Design choices (Performance } \\
\text { \& Remanufacturability) } \\
\text { - Disposal of cores } \\
\text { - Number of allowances to } \\
\text { purchase or sell }\end{array}$ & $\begin{array}{l}- \text { Prices of new and } \\
\text { remanufactured products } \\
\text { - Credit for core returns }\end{array}$ \\
\hline $\begin{array}{l}\text { Parameters requiring } \\
\text { relatively lesser additional } \\
\text { effort for estimation }\end{array}$ & $\begin{array}{l}\text { - Fixed and variable costs of } \\
\text { manufacturing, } \\
\text { remanufacturing, and core } \\
\text { collection } \\
\text { - Economic life of products } \\
\text { - Capacities consumed per } \\
\text { unit of new and } \\
\text { remanufactured products } \\
\text { - Inventory holding costs for } \\
\text { new and remanufactured } \\
\text { products, and product cores }\end{array}$ & $\begin{array}{l}\text { - Disposal costs } \\
\text { - Market prices of allowances }\end{array}$ & \\
\hline $\begin{array}{l}\text { Parameters requiring } \\
\text { relatively greater additional } \\
\text { effort for estimation }\end{array}$ & $\begin{array}{l}\text { - Backordering costs for new } \\
\text { and remanufactured } \\
\text { products }\end{array}$ & $\begin{array}{l}\text { - Design costs for } \\
\text { performance and } \\
\text { remanufacturability } \\
\text { - Emissions attributable to } \\
\text { the manufacture and } \\
\text { remanufacture of a unit of a } \\
\text { product }\end{array}$ & $\begin{array}{l}\text { - Demand parameters: } \\
\text { Market potential, Price } \\
\text { sensitivity, Substitutability } \\
\text { of new and remanufactured } \\
\text { counterparts, Sensitivity to } \\
\text { product performance, } \\
\text { Sensitivities to price and } \\
\text { performance of competing } \\
\text { products } \\
\text { - Sensitivity of core returns to } \\
\text { core credit }\end{array}$ \\
\hline Constraints & $\begin{array}{l}\text { - Available manufacturing } \\
\text { and remanufacturing } \\
\text { capacities } \\
\text { - Inventory balance for new } \\
\text { and remanufactured } \\
\text { products, and product cores }\end{array}$ & $\begin{array}{l}\text { - Design standard of } \\
\text { performance } \\
\text { - Voluntarily specified } \\
\text { emissions limits } \\
\text { - Allowances available for } \\
\text { purchase } \\
\text { - Allowance inventory } \\
\text { balance }\end{array}$ & \\
\hline
\end{tabular}

Figure 2 Model elements.

discount factor as $\alpha \in(0,1)$-across all products and time periods, expressed as follows: revenue from sales of new and remanufactured products + net revenue from allowances - cost of product design - cost of manufacturing and remanufacturing - cost of core collection - cost of holding inventory - cost of back-ordering customer demand - cost of disposal of cores and nonremanufacturable components. The key factors that constrain profit maximization can be classified under two categories-operational and environmental. Operational factors include manufacturing and remanufacturing capacities (Constraints 2, 3, and 4), whereas environmental factors include design standards (Constraint 1), availability of emissions allowances (Constraint 9), voluntarily specified emissions limits (Constraint 8), and emissions caps (Constraint 10).

$$
\begin{aligned}
& \text { Maximize } \sum_{t=1}^{T} \sum_{i=1}^{M} \alpha^{t}\left[P_{i t n} d_{i t n}+P_{i t r} d_{i t r}\right] \\
& \quad+\sum_{t=1}^{T} \alpha^{t} \phi_{t}\left[\mathrm{~V}_{t}-B_{t}\right] \\
& \quad-\sum_{i=1}^{M}\left[\left(\xi_{1 i} Q_{i 0}\right)^{2}+\left(\xi_{2 i} \Theta_{i 0}\right)^{2}\right] \\
& \quad-\sum_{t=1}^{T} \sum_{i=1}^{M} \alpha^{t}\left[\delta_{i t n} f_{i t n}\right. \\
& \quad+c_{i t n} X_{i t}+\delta_{i t r} f_{i t r}+c_{i t r} Y_{i t}+\delta_{i t c} f_{i t c} \\
& \quad+\left(\Psi_{i t}+c_{i t c}\right) R_{i t}+h_{i t n} I_{i t n}+h_{i t r} I_{i t r} \\
& \quad+h_{i t c} I_{i t c}+u_{i t n} \sigma_{i t n}+u_{i t r} \sigma_{i t r} \\
& \left.\quad+\rho_{i t}\left[\left\{1-\left(\Theta_{i 0}+\Theta_{i B}\right)\right\} Y_{i t}+W_{i t}\right]\right]
\end{aligned}
$$


Subject to constraints: ${ }^{9}$

\begin{tabular}{|c|c|c|}
\hline$Q_{i 0} \geq Q_{i,(\mathrm{std})}$ & $i=1,2, \ldots, M$ & (Constraint 1 ) \\
\hline$\sum_{i=1}^{M}\left[k_{a i n} X_{i t}+k_{a i r} Y_{i t}\right] \leq K_{a t}$ & $t=1,2, \ldots, T$ & (Constraint 2) \\
\hline$\sum_{i=1}^{M} k_{\min } X_{i t} \leq K_{m t n}$ & $t=1,2, \ldots, T$ & (Constraint 3 ) \\
\hline$\sum_{i=1}^{M} k_{m i r} Y_{i t} \leq K_{m t r}$ & $t=1,2, \ldots, T$ & (Constraint 4) \\
\hline$\stackrel{i}{i k}_{i k} \leq S_{i, k-\tau_{i}, n}+S_{i, k-\tau_{i}, r}$ & $i=1,2, \ldots, M ; k=\tau_{i}+1, \tau_{i}+2, \ldots, T$ & (Constraint 5) \\
\hline$W_{i k} \leq I_{i, k-1, c}+R_{i k}$ & $i=1,2, \ldots, M ; k=\tau_{i}+1, \tau_{i}+2, \ldots, T$ & (Constraint 6) \\
\hline$Y_{i k} \leq I_{i, k-1, c}+R_{i k}-W_{i k}$ & $i=1,2, \ldots, M ; k=\tau_{i}+1, \tau_{i}+2, \ldots, T$ & (Constraint 7) \\
\hline$E_{t} \leq l_{t}$ & $t=1,2, \ldots, T$ & (Constraint 8) \\
\hline $0 \leq B_{t} \leq \eta_{t}$ & $t=1,2, \ldots, T$ & (Constraint 9) \\
\hline$E_{t} \leq \beta_{t-1}+B_{t}$ & $t=1,2, \ldots, T$ & (Constraint 10) \\
\hline $0 \leq V_{t} \leq \beta_{t-1}+B_{t}-E_{t}$ & $t=1,2, \ldots, T$ & (Constraint 11) \\
\hline $0 \leq \Theta_{i 0} \leq 1-\Theta_{i B}$ & $i=1,2, \ldots, M$ & \\
\hline$\Psi_{i t}, X_{i t}, \bar{P}_{i t n}, P_{i t r}, d_{i t n}, d_{i t r} \geq 0$ & $i=1,2, \ldots, M ; t=1,2, \ldots, T$ & \\
\hline$W_{i k}, Y_{i k} \geq 0$ & $i=1,2, \ldots, M ; k=\tau_{i}+1, \tau_{i}+2, \ldots, T$ & \\
\hline$I_{i k c}, R_{i k}, W_{i k}, Y_{i k}=0$ & $i=1,2, \ldots, M ; k=1,2, \ldots, \tau_{i}$ & \\
\hline $\begin{array}{l}I P_{i, 0, n}, I P_{i, 0, r}, \sigma_{i T n}, \sigma_{i T r}=0 \\
\beta_{0}=0\end{array}$ & $i=1,2, \ldots, M$ & \\
\hline
\end{tabular}

\section{Implementation}

In this section, we discuss issues with implementing the modeling approach presented in the previous section. Although it is clear that the two companies interviewed feel the need for holistic decision models that mesh various interactions together, neither company currently undertakes such an effort due to a lack of appropriate tools and data. To the best of our knowledge, the same is true in other industries.

Our primary goal in this article is to demonstrate how a decision model based on a variety of observed interactions can be developed in a systematic manner. In practice, users would modify our model to capture the specific strategic, tactical, and environmental considerations of a given firm and populate it with firm-specific data. The approach requires the characterization and estimation of several relationships and parameters, some of which are known, and others of which require data that most firms do not normally collect — at least systematically. On the basis of the information gathered from the interviews, we classify the model's parameters in terms of relative additional effort required in estimating them (see figure 2). Certain data that would help in estimating specific parameters are likely to currently exist, although in a fragmented form across organizational functions. Fixed and variable costs of manufacturing and remanufacturing and inventory holding costs can be obtained from standard accounting systems, but this would require some effort if such data are not already used routinely. The design function would have reasonable estimates of the expected economic life of products. Manufacturing and remanufacturing capacities are reasonably known to the manufacturing and remanufacturing functions, as are disposal costs (or salvage values) of cores. The finance and accounting functions would have data on emissions allowances, where applicable.

Estimating the remaining relationships and associated parameters would require creativity and effort, because the necessary data are unavailable even to people charged with making related decisions. The feeling at the companies interviewed is people often make assumptions that feed decision-making without supporting data. For example, Company A is taking some steps 
to understand demand parameters, but the belief is that much more improvement is possible with respect to assessing how customers value various attributes, such as price, performance, and the offerings by the competition. In addition, structured efforts are required if the company is to assess the extent of cannibalization of new products by remanufactured products (e.g., see Guide and Li 2007), the opportunity costs of not being able to meet customer demand, and the sensitivity of core returns to the credit offered. The marketing functions at the companies interviewed currently have a sense as to the general nature of these relationships, but formal assessments are lacking.

On a crucial yet exciting note, the model developed in this article highlights the importance of LCAs in their currently untapped ability to inform managerial decision-making. Of specific relevance to the model developed in this article is the LCA model for remanufactured engines by Smith and Keoleian (2004), who provide numeric estimates of air emissions, solid waste generation, material consumption, and real cost savings attributable to remanufacturing. Such information in LCAs can be valuable in estimating the model's parameters, thus enabling the bridging of operational and environmental decisions, such as the mix between new and remanufactured products, to meet environmental targets.

\section{Model Solution: Illustration}

As discussed in the previous section, it is currently impossible to use real data to populate the model. To demonstrate the importance of considering environmental factors in making managerial decisions, however, we populate and solve the model with illustrative data for two products over a time horizon of ten periods. Supplementary Table D1 in Supplementary Appendix D on the Web summarizes the base data used for the illustrations in this section. ${ }^{10}$ Supplementary Appendix $\mathrm{E}$ on the Web provides an overview of the characteristics of Products 1 and 2 assumed in the base data. For clarity, we present results in the form of graphs in Supplementary Appendix $\mathrm{F}$ on the Web. The graphs are annotated with corresponding variations of the base data.

A variety of commercially available optimization software exists for solving nonlinear opti- mization problems, allowing for settings that typically trade off speed with solution quality (see NEOS [2008] and Fourer [2005] for detailed discussions). We solve the model using the demo versions of AMPL and the MINOS solver ${ }^{11}$ on a modest Intel 2.00 gigahertz $(\mathrm{GHz})$ personal computer with $2 \mathrm{~GB}$ of RAM running Windows XP. See Supplementary Appendix G on the Web for brief descriptions of AMPL and MINOS. Given the nonlinearity of the model, we run 100 repetitions of the solver for each numerical scenario to select the best among the 100 solutions. Average computation time for 100 repetitions of the solver (across numerical scenarios) was less than 5 minutes. We anticipate that practical implementations of the model would be more involved (e.g., greater product variety), however, and would therefore require greater computational effort.

We briefly reflect, in turn, on how the consideration of three environmental factors-the emissions limit, the market price of allowances, and the core disposal cost-affects decisions pertaining to the product mix (Supplementary Figures F1 and F2 in Supplementary Appendix $\mathrm{F}$ on the Web), product design (Supplementary Figures F3 and F4 in Supplementary Appendix $\mathrm{F}$ on the Web), pricing (Supplementary Figure F5 in Supplementary Appendix F on the Web), and the credit offered to induce returns of cores (Supplementary Figure F6 in Supplementary Appendix $F$ on the Web). In each of the figures, the bar on the extreme right, labeled All Factors Considered, represents the optimal decision when all of the three environmental factors are considered (i.e., optimal solution for the data in Supplementary Table D1 in Supplementary Appendix $\mathrm{D}$ on the Web), whereas the bars on the left represent the optimal decisions when one of the three factors, in turn, is not considered in the decision-making. Supplementary Figure F7 in Supplementary Appendix F on the Web depicts the profit impact of these factors.

\section{Emissions Limit}

To focus on the importance of factoring in the emissions limit in the decision-making, we contrast the situation in which the companies do not consider the emissions limit (labeled as 
Emissions Limit Not Considered in Supplementary Figures F1 through F6 in Supplementary Appendix $F$ on the Web) with the situation in which all factors are considered. In other words, we contrast the optimal solution when emissions are assumed to be unconstrained from an operations planning standpoint (current industry practice) with the situation in which the emissions limit is an active constraint at the optimal solution, as is the case with the optimal solution for the data in Supplementary Table D1 in Supplementary Appendix D on the Web. As the emissions limit becomes an active constraint, the product mix changes significantly; the overall production level decreases, and the level of remanufacturing activity (relative to manufacturing new) increases. ${ }^{12}$ The increase in remanufacturing is due to the lower emissions as compared with manufacturing new. As per our data, when emissions are not considered in operations planning, both manufacturing and remanufacturing are almost entirely focused on the more profitable Product 2, and, therefore, significant investments are made in the performance and remanufacturability of Product 2. When the emissions constraint becomes active, however, Product 1 , which has relatively lower emissions during production as compared with Product 2, also becomes attractive to produce, with the remanufacturability for Product 1 increasing relative to the unconstrained emissions case. Because we model the demand for a product as increasing in its performance, the prices of both new and remanufactured versions of Product 1 are respectively greater when the emissions limit is not considered. Finally, as emissions become constrained, the credit offered for cores increases, because remanufacturing is more attractive under an active emissions constraint.

\section{Market Price of Allowances}

To focus on the importance of factoring in the price of emissions allowances, we contrast the situation in which the companies do not consider the price of allowances (labeled as Allowance Price Not Considered in Supplementary Figures F1 through F6 in Supplementary Appendix F on the Web) with the situation in which all factors are considered. In other words, we contrast the optimal solution in which allowances are regarded as costless from an operations planning standpoint (current industry practice) with the situation in which allowances have a nonzero cost, as is the case with the data in Supplementary Table D1 in Supplementary Appendix D on the Web. ${ }^{13}$ Similar to the discussion for the emissions limit above, when the price of allowances is considered, the product mix changes, with the level of remanufacturing activity for Product 1 (relative to new manufacture) increasing. This increase is due to the lower emissions attributable to remanufacturing Product 1 as compared with manufacturing new and the correspondingly lower total cost incurred for emissions allowances. The reason for the slight decrease in remanufacturing activity for Product 2 is the following. When the price of allowances is ignored, the remanufacturability of the more profitable Product 2 is greater than that of Product 1. As allowances become costly, however, Product 1 , which has relatively lower emissions during production as compared with Product 2, becomes attractive for remanufacturing; the remanufacturability for Product 1 increases and the remanufacturability of Product 2 decreases relative to the zero-allowance price case. Because in our model the variable cost of remanufacturing increases with a lack of remanufacturability, the level of remanufacturing for Product 2 decreases when the market price of allowances is factored in the decision-making. Finally, as allowances become expensive, the credit offered for cores of both products increases (marginally, though, for Product 2) to facilitate remanufacturing activity.

\section{Disposal Costs}

Finally, to focus on the importance of factoring in the cost of disposing of nonremanufacturable portions of returning cores, we contrast the situation in which the companies do not consider the disposal cost of cores (labeled as Disposal Cost Not Considered in Supplementary Figures F1 through F6 in Supplementary Appendix F on the Web) with the situation in which all factors are considered. In other words, we contrast the optimal solution, in which disposal is costless from an operations planning standpoint (current industry practice), with the situation in which disposal is costly, as is the case with the data in 
Supplementary Table D1 in Supplementary Appendix D on the Web. ${ }^{14}$ Similar to the discussion for the market price of allowances, when the cost of disposal is considered, the level of remanufacturing (relative to new manufacture) increases for Product 1 but decreases for Product 2. It is interesting to note that when core disposal is regarded as costless, the incentive to invest in product remanufacturability diminishes considerably-to the extreme in our illustrative data-because any nonremanufacturable portions of cores can be disposed of without cost. ${ }^{15}$ Also, as disposal becomes costly, the increase in product remanufacturability justifies an increased credit for cores to facilitate remanufacturing activity. ${ }^{16}$

As the above results illustrate, joint operational and environmental decision-making involves complex and important trade-offs that are not currently being captured in practice. Without a decision-making tool capable of capturing these trade-offs holistically, firms are at risk of making suboptimal decisions with adverse consequences for both firm profitability and environmental outcomes.

\section{Conclusion}

The need for explicit consideration of environmental costs and constraints within operations planning is becoming critical to corporate management. An increasing number of firms across countries face environmental regulations at various stages in the production and consumption of their products. The nonlinear programming approach posited in this article can treat key managerial trade-offs starting with product design, through production, to the end of the product's economic life, and across multiple time periods and products. Although we present a characteristic model based on detailed interviews with top managers from two leading competitors in the medium and heavy-duty diesel engine industry (with the possibility that certain model elements may be context specific, e.g., shared production capacity between new and remanufactured engines, voluntary emissions limits, permits for emissions, and various functional relationships), the approach in itself is flexible enough to accommodate a range of applications. In particular, the ability to treat nonlinear relation- ships makes our approach capable of refinement and managerial application. It allows us to treat a spectrum of environmental considerations, such as design standards and emissions targets, as well as strategic aspects, such as product pricing, competition, and the cannibalization of new products by remanufactured products. The work is timely and pertinent to practitioners, many of whom are just beginning to deal with complex trade-offs in meeting environmental targets.

We recognize that the effort involved in characterizing the nature of relationships and associated parameters within the model is significant but possible through the implementation of creative organizational and informational structures to systematically collect relevant data. We hope that this article successfully sheds light on the need not only to involve all departments within a business in making sensible economic and environmental decisions but also for industrial ecologists and business managers to work together to implement meaningful decision models that can have definite economic and environmental impact.

\section{Acknowledgements}

We thank Brian Lewallen, General Manager, Detroit Diesel Remanufacturing, and two managers from another major diesel engine manufacturer/remanufacturer for the significant time and effort they devoted to discussing relevant issues in the industry. Financial support from the Natural Sciences and Engineering Research Council (NSERC) of Canada is gratefully acknowledged.

\section{Appendices \\ Appendix A. Interview Questions}

We provided the following questions in advance of our detailed phone interviews with the managers from the two companies:

1. Could you reflect on the various types of environmental regulations (current as well as future) that your company faces, starting from product design and materials through end-of-life product recovery/disposal? 
2. What are the levers within the control of your company to influence the costs/impacts of such legislation (e.g., pricing, product design, abatement, recycling/remanufacturing)?

3. Is there an effort to mesh traditional capacity and production decisions with decisions that impact legislative costs (e.g., mix between new and remanufactured products)?

4. Is there an effort to holistically consider how a spectrum of decisions (such as product design choices, process choices, product mix, etc.) affect the overall environmental impact or legislative costs?

The phone interviews provided us with the majority of the information reflected in this article. We obtained the remaining information through responses to our follow-up questions below, which we asked by e-mail:

1. Could you characterize how the design cost of an engine is impacted by the desired performance and remanufacturability? e.g., Does the cost of design increase at an increasing rate with increase in performance? Does the cost of design increase at an increasing rate with increase in remanufacturability? Is the cost of design increasing with respect to a combination of performance and remanufacturability?

2. Does the performance of the engine impact remanufacturing costs? In other words, is it more expensive to remanufacture a higher performance engine than a lower performance engine, or is the remanufacturing cost relatively unaffected by the engine's performance?

3. Does the manufacturing cost for a new engine increase with the engine's degree of remanufacturability? Or is it relatively unaffected?

4. Are there any fixed infrastructural costs involved in the collection of cores (e.g., setting up returns networks, logistics, etc.)?

5. How often does your company typically change prices on new and remanufactured engines?

\section{Appendix B. Notation}

\section{Decision Variables}

$B_{t}=$ Number of emissions allowances purchased in period $t$

$P_{i t n}=$ Price of new product $i$ in period $t$

$P_{i t r}=$ Price of remanufactured product $i$ in pe$\operatorname{riod} t$

$\Psi_{i t}=$ Credit offered per returned core of product $i$ in period $t$

$Q_{i 0}=$ Performance of product $i$

$\Theta_{i 0}=$ Remanufacturability of product $i$

$V_{t}=$ Number of emissions allowances sold in period $t$

$W_{i t}=$ Number of cores of product $i$ disposed of in period $t$

$X_{i t}=$ Quantity of product $i$ manufactured new in period $t$

$Y_{i t}=$ Quantity of product $i$ remanufactured in period $t$

\section{Other Variables and Parameters}

$a_{i t n}=$ Market potential of new product $i$ in period $t$

$a_{i t r}=$ Market potential of remanufactured product $i$ in period $t$

$\alpha=$ Discount factor

$b_{i t n}, b_{i t n r}, b_{i t n}^{\mathrm{C}}, b_{i t n q}, b_{i t n q}^{\mathrm{C}}$

$=$ Sensitivity parameters of demand for new product $i$ in period $t$

$b_{i t r}, b_{i t r n}, b_{i t r}^{\mathrm{C}}, b_{i t r q}, b_{i t r q}^{\mathrm{C}}$

$=$ Sensitivity parameters of demand for remanufactured product $i$ in period $t$

$\beta_{t}=$ Inventory of allowances at end of pe$\operatorname{riod} t$

$c_{i t c}=$ Variable cost of collecting cores of product $i$ in period $t$

$\tilde{c}_{i t n 0}, \tilde{c}_{i t n}=$ Coefficients in the variable cost of manufacturing new product $i$ in pe$\operatorname{riod} t$

$c_{i t n}=$ Variable cost of manufacturing new product $i$ in period $t$

$\tilde{c}_{i t r 0}, \tilde{c}_{i t r}=$ Coefficients in the variable cost of remanufacturing product $i$ in period $t$

$c_{i t r}=$ Variable cost of remanufacturing product $i$ in period $t$ 
$d_{i t n}=$ Demand for new product $i$ in period $t$

$d_{i t r}=$ Demand for remanufactured product $i$ in period $t$

$\delta_{i t c}=$ Indicator function for collection of cores of product $i$ in period $t$

$\delta_{i t n}=$ Indicator function for manufacture of new product $i$ in period $t$

$\delta_{i t r}=$ Indicator function for remanufacture of product $i$ in period $t$

$e_{i n}=$ Emissions attributable to the manufacture of a unit of new product $i$

$e_{i r}=$ Emissions attributable to the remanufacture of a unit of product $i$

$E_{t}=$ Total emissions attributable to manufacturing and remanufacturing in period $t$

$\eta_{t}=$ Number of allowances available for purchase in period $t$

$f_{i t c}=$ Fixed cost of collecting cores of product $i$ in period $t$

$f_{i t n}=$ Fixed cost of manufacturing new product $i$ in period $t$

$f_{i t r}=$ Fixed cost of remanufacturing product $i$ in period $t$

$h_{\text {itc }}=$ Unit inventory holding cost of cores of product $i$ in period $t$

$h_{i t n}=$ Unit inventory holding cost of new product $i$ in period $t$

$h_{i t r}=$ Unit inventory holding cost of remanufactured product $i$ in period $t$

$I_{i t c}=$ Inventory of cores of product $i$ at end of period $t$

$I_{i t n}=$ Inventory of new product $i$ at end of period $t$

$I_{i t r}=$ Inventory of remanufactured product $i$ at end of period $t$

$I P_{i t n}=$ Inventory position of new product $i$ at end of period $t$

$I P_{i t r}=$ Inventory position of remanufactured product $i$ at end of period $t$

$k_{a i n}=$ Assembly capacity consumed per unit of new product $i$

$k_{a i r}=$ Assembly capacity consumed per unit of remanufactured product $i$

$k_{\min }=$ Machining capacity consumed per unit of new product $i$

$k_{\text {mir }}=$ Machining capacity consumed per unit of remanufactured product $i$
$K_{a t}=$ Assembly capacity available in pe$\operatorname{riod} t$

$K_{m t n}=$ Machining capacity available for manufacturing new in period $t$

$K_{m t r}=$ Machining capacity available for remanufacturing in period $t$

$l_{t}=$ Voluntary emissions limit in period $t$

$\lambda_{i t}=$ Sensitivity of core returns to core credit offered for product $i$ in period $t$

$P_{i t}^{\mathrm{C}}=$ Price of competitor's product $i$ in pe$\operatorname{riod} t$

$\phi_{t}=$ Unit market price of allowances in period $t$

$Q_{i, \text { std }}=$ Performance standard for product $i$

$Q_{i 0}^{C}=$ Performance of competitor's product $i$

$R_{i t}=$ Returns of cores of product $i$ in period $t$

$\rho_{i t}=$ Unit cost of disposing of cores of product $i$ in period $t$

$S_{\text {itn }}=$ Sales of new product $i$ in period $t$

$S_{i t r}=$ Sales of remanufactured product $i$ in period $t$

$\sigma_{i t n}=$ Back-ordered quantity of new product $i$ at end of period $t$

$\sigma_{i t r}=$ Back-ordered quantity of remanufactured product $i$ at end of period $t$

$\tau_{i}=$ Economic life of product $i$

$\Theta_{i B}=$ Inherent level of remanufacturability of product $i$

$u_{i t n}=$ Unit cost of back-ordering new product $i$ in period $t$

$u_{i t r}=$ Unit cost of back-ordering remanufactured product $i$ in period $t$

$\xi_{1 i}=$ Design cost coefficient of performance for product $i$

$\xi_{2 i}=$ Design cost coefficient of remanufacturability for product $i$

\section{Appendix C. Additional Model Assumptions}

Following is a list of additional assumptions we made in developing the decision model in the Model Development section. The assumptions are made for expositional purposes and can be relaxed easily. 
- Design costs are not shared across products. Product design decisions are not revisited during the planning horizon.

- One allowance accounts for one unit of emissions. Allowances are bankable.

- Each postuse product translates into one core for the purpose of remanufacturing.

- Facilities, equipment, and processes necessary for manufacture, core collection, and core remanufacturing are assumed to be already present; fixed costs in each period represent setup costs.

- Demand must be met if units are available in inventory. Unmet demand is backordered. Customer demand across all time periods must be met by the end of the planning horizon.

\section{Notes}

1. We have also visited the facilities of the two companies multiple times over the past few years.

2. That is, convex, linear, or concave and increasing or decreasing.

3. There is a sense, however, that customers in developing markets are now gravitating toward preferences similar to those of customers in developed markets.

4. This was a surprising finding. One of the managers interviewed explained that customers in developed markets value up-time and the comparable performance afforded by remanufactured engines, whereas in developing markets, where up-time is less critical and labor costs are low, repair is preferred as a less expensive alternative to buying a remanufactured engine.

5. A positive value of $I P_{i t n}$ or $I P_{i t r}$ indicates inventory on hand, whereas a negative value indicates a backordered quantity.

6. Alternatively, the interviewed companies also influence the returns of cores through an upfront "core charge" at the time of sale, which is refunded when the core is returned after use. This is analogous to a deposit-refund system, which various countries have used successfully to encourage the recycling of products such as beverage containers and automotive batteries. Evidence suggests that deposit-refund systems are more effective and cost-efficient than other methods to reduce waste. For example, the deposit-refund system for beverage containers in the United States has been very effective in increasing the percentage of containers recycled (EPA 2001). We believe that upfront core charges will be similarly effective in inducing core returns, but empirical evidence is unavailable.

7. For expositional convenience, we assume that in any given period, only cores sold $\tau_{i}$ periods ago will return for remanufacture, where $\tau_{i}$ is the economic life of product $i$. A more general formulation could allow for core returns from sales in any prior period. We also noted from the interviews that there is a limited difference in the economic life of new and remanufactured versions of an engine, although there is an upper bound on the number of times a core can be remanufactured. For over-theroad truck engines, it is common to remanufacture a core up to five times.

8. Company B is not constrained by the market availability of allowances and also does not face a mandated limit on $\mathrm{CO}_{2}$ emissions. Under ETS, however, all $\mathrm{CO}_{2}$ emissions have to be accounted for by allowances that have market value. From our model, the shadow price associated with the voluntary emissions constraint can be used to assess the impact on profitability of voluntarily limiting $\mathrm{CO}_{2}$ emissions. The model can be easily adapted to accommodate a mandated limit or constrained market availability of allowances, if applicable.

9. Nonnegativity constraints, bounds, and initial and terminal conditions are not numbered in the model development.

10. Our illustration assumes that data across all time periods are known in advance. In practice, a rolling planning horizon may be employed, so that the model can be solved with data that are continuously updated.

11. AMPL stands for "A Modeling Language for Mathematical Programming." Demo versions of AMPL and MINOS are available at http://www.ampl.com.

12. A core may return several times for remanufacture.

13. The emissions constraint is active in both cases.

14. The emissions constraint is again active in both cases.

15. When the design choice of remanufacturability equals zero for product $i$, the level of remanufacturability is just the inherent level $\Theta_{i B}$, which implies that a remanufactured product $i$ is almost entirely rebuilt.

16. The companies interviewed do not currently face mandated product take-back. Therefore, disposal costs are only incurred for the nonremanufacturable portions of only those cores that return for remanufacture. 


\section{References}

Atasu, A., V. D. R. Guide, Jr., and L. N. van Wassenhove. 2008. Product reuse economics in closedloop supply chain research. Production and Operations Management 17(5): 1-14.

Bloemhof-Ruwaard, J. M., P. van Beek, L. Hordijk, and L. N. van Wassenhove. 1995. Interactions between operational research and environmental management. European Journal of Operational Research 85(2): 229-243.

Corbett, C. J. and P. R. Kleindorfer. 2001a. Environmental management and operations management: Introduction to Part 1 (Manufacturing and eco-logistics). Production and Operations Management 10(2): 107-111.

Corbett, C. J. and P. R. Kleindorfer. 2001b. Environmental management and operations: Introduction to Part 2 (Integrating operations and environmental management systems). Production and Operations Management 10(3): 225227.

EC (European Commission). 2001. Green paper on integrated product policy. Brussels, Belgium: EC.

EC. 2008. Policies. http://ec.europa.eu/environment/ policy_en.htm. Accessed 16 September 2008.

EPA (U.S. Environmental Protection Agency). 2001. The United States experience with economic incentives for protecting the environment. EPA-240-R-01001. Washington, DC: EPA.

EPA. 2005. Acid rain program: 2004 progress report. Washington, DC: EPA.

Environmental Resources Management. 2005. Study and assessment of available information for a pilot project on a teak garden chair: Final report. Oxford, UK: Environmental Resources Management.

Fahimnia, B., L. H. S. Luong, and R. M. Marian. 2007. Modeling and optimization of aggregate production planning: A genetic algorithm approach. Proceedings of the World Academy of Science, Engineering, and Technology 1(1): 1-6.

Fourer, R. 2005. Nonlinear programming frequently asked questions. Evanston, IL: Optimization Technology Center of Northwestern University and Argonne National Laboratory www-unix.mcs.anl.gov/otc/ Guide/faq/nonlinear-programming-faq.html. Accessed 15 September 2008.

Ginter, P.M. and J. M. Starling. 1978. Reverse distribution channels for recycling. California Management Review 20(3): 73-82.

Greenberg, H. J. 1995. Mathematical programming models for environmental quality control. Operations Research. 43(4): 578-622.

Guide, V. D. R., Jr. and K. Li. 2007. The potential for cannibalization of new product sales by remanu- factured products. Working paper, Pennsylvania State University.

Guide, V. D. R., Jr. and L. N. van Wassenhove. 2006a. Closed-loop supply chains: An introduction to the feature issue, Part 1. Production and Operations Management 15(3): 345-350.

Guide, V. D. R., Jr. and L. N. van Wassenhove. 2006b. Closed-loop supply chains: An introduction to the feature issue, Part 2. Production and Operations Management 15(4): 471-472.

Gungor, A. and S. M. Gupta. 1999. Issues in environmentally conscious manufacturing and product recovery: A survey. Computers and Industrial Engineering 36(4): 811-853.

Heizer J., and B. Render. 2005. Operations management. 8th ed. Upper Saddle River, NJ: Pearson Prentice Hall.

Holt, C. C., F. Modigliani, and H. S. Simon. 1955. Linear decision rule for production and employment scheduling. Management Science 2(1): 1-30.

Holt, C. C., F. Modigliani, J. Muth, and H. S. Simon. 1956. Derivation of linear decision rule for production and employment. Management Science 2(2): 159-177.

Kleindorfer, P. R., K. Singhal, and L. N. van Wassenhove. 2005. Sustainable operations management. Production and Operations Management. 14(4): 482-492.

Lund, R. T. 1984. Remanufacturing. Technology Review 87(2): 19-29.

Matthews, H. S. and R. Lifset. 2007. The life-cycle assessment and industrial ecology communities: Expanding boundaries together. Journal of Industrial Ecology. 11(4): 1-4.

Mendoza, G. A. and H. Martins. 2006. Multi-criteria decision analysis in natural resource management: A critical review of methods and new modelling paradigms. Forest Ecology and Management 230(13): $1-22$.

Mula, J., R. Poler, J. P. Garcia-Sabater, and F. C. Lario. 2006. Models for production planning under uncertainty: A review. International Journal of Production Economics 103(1): 271-285.

Nam, S. J. and R. Logendran. 1992. Aggregate production planning: A survey of models and methodologies. European Journal of Operational Research 61(3): 255-272.

NEOS (Network-Enabled Optimization System). 2008. Optimization software guide. www-fp.mcs. anl.gov/OTC/Guide/SoftwareGuide/index.html. Accessed 14 September 2008.

Nokia Corporation. 2005. Integrated product policy pilot project: Life cycle environmental issues of mobile phones. Espoo, Finland: Nokia. 
Rajaram, K. and C. J. Corbett. 2002. Achieving environmental and productivity improvements through model-based process redesign. Operations Research 50(5): 751-763.

Scheer, D. and F. Rubik, Eds. 2005. Governance of integrated product policy: In search of sustainable production and consumption. Sheffield, UK: Greenleaf.

Smith, V. M., and G. A. Keoleian. 2004. The value of remanufactured engines: Life-cycle environmental and economic perspectives. Journal of Industrial Ecology 8(1-2): 193-221.

Spengler, T., H. Puchert, T. Penkuhn, and O. Rentz. 1997. Environmental integrated production and recycling management. European Journal of Operational Research 97(2): 308-326.

Stuart, J. A., J. C. Ammons, and L. J. Turbini. 1999. A product and process selection model with multidisciplinary environmental considerations. Operations Research 47(2): 221-234.

Tukker, A. 2006. Identifying priorities for environmental product policy. Journal of Industrial Ecology 10(3): 1-4.

Tukker, A. and B. Jansen. 2006. Environmental impacts of products: A detailed review of studies. Journal of Industrial Ecology 10(3): 159-182.

Wang, R. C. and T. F. Liang. 2005. Aggregate production planning with multiple fuzzy goals. Interna- tional Journal of Advanced Manufacturing Technology 25(5-6): 589-597.

Wu, C. C. and N. B. Chang. 2004. Corporate optimal production planning with varying environmental costs: A grey compromise programming approach. European Journal of Operational Research 155(1): 68-95.

\section{About the Authors}

Ravi Subramanian is an assistant professor of operations management at the College of Management, Georgia Institute of Technology, in Atlanta, Georgia. Brian Talbot is the David B. Hermelin Professor of Business Administration and professor of operations and management science at the Stephen M. Ross School of Business, University of Michigan, in Ann Arbor, Michigan. He also served as interim director of the Graham Environmental Sustainability Institute at the University of Michigan. Sudheer Gupta is an associate professor of technology and operations management at the Faculty of Business Administration, Simon Fraser University, in Burnaby, British Columbia, Canada.

\section{Supplementary Material}

Additional Supplementary Material may be found in the online version of this article:

Supplement S1: This supplementary material contains the appendices that include the data and figures of results for the numerical illustrations in the Model Solution: Illustration section. In particular, Supplementary Table D1 in Supplementary Appendix D summarizes the base data used for the illustrations. Supplementary Appendix E provides an overview of the characteristics of Products 1 and 2 assumed in the base data. Results in the form of graphs are included in Supplementary Appendix F. The graphs are annotated with corresponding variations of the base data. Supplementary Appendix G includes brief descriptions of AMPL (mathematical programming language) and MINOS (nonlinear solver), which we used to solve the model.

Please note: Wiley-Blackwell is not responsible for the content or functionality of any supplementary materials supplied by the authors. Any queries (other than missing material) should be directed to the corresponding author for the article. 